\title{
GPCR Partners as Cancer Driver Genes: Association with PH-Signal Proteins in a Distinctive Signaling Network
}

\author{
Jeetendra Kumar Nag, Hodaya Malka, Priyanga Appasamy, Shoshana Sedley and Rachel Bar-Shavit*iD
}

Citation: Nag, J.K.; Malka, H.; Appasamy, P.; Sedley, S.; Bar-Shavit, R. GPCR Partners as Cancer Driver Genes: Association with PH-Signal Proteins in a Distinctive Signaling Network. Int. J. Mol. Sci. 2021, 22, 8985. https://doi.org/10.3390/ ijms22168985

Academic Editor: Silvie Rimpelova

Received: 29 July 2021

Accepted: 17 August 2021

Published: 20 August 2021

Publisher's Note: MDPI stays neutra with regard to jurisdictional claims in published maps and institutional affiliations.

Copyright: (C) 2021 by the authors Licensee MDPI, Basel, Switzerland. This article is an open access article distributed under the terms and conditions of the Creative Commons Attribution (CC BY) license (https:// creativecommons.org/licenses/by/ $4.0 /)$.
Sharett Institute of Oncology, Hadassah-Hebrew University Medical Center, POB 12000, Jerusalem 91120, Israel; jeetendr.nag@mail.huji.ac.il (J.K.N.); hodaya.malka@mail.huji.ac.il (H.M.); a.priyanga18@gmail.com (P.A.); shanisedley@gmail.com (S.S.)

* Correspondence: Rachelbar@ekmd.huji.ac.il

\begin{abstract}
The essential role of G-protein coupled receptors (GPCRs) in tumor growth is recognized, yet a GPCR based drug in cancer is rare. Understanding the molecular path of a tumor driver gene may lead to the design and development of an effective drug. For example, in members of protease-activated receptor (PAR) family (e.g., $\mathrm{PAR}_{1}$ and $\mathrm{PAR}_{2}$ ), a novel $\mathrm{PH}$-binding motif is allocated as critical for tumor growth. Animal models have indicated the generation of large tumors in the presence of $\mathrm{PAR}_{1}$ or $\mathrm{PAR}_{2}$ oncogenes. These tumors showed effective inhibition when the $\mathrm{PH}-$ binding motif was either modified or were inhibited by a specific inhibitor targeted to the $\mathrm{PH}$ binding motif. In the second part of the review we discuss several aspects of some cardinal GPCRs in tumor angiogenesis.
\end{abstract}

Keywords: G-protein coupled receptors (GPCRs); protease-activated receptors (PARs); angiogenesis

\section{Introduction}

Proteases in cancer are long known as tightly associated with tumor progression, facilitating the spread of tumor metastasis. While the world of protease takes a pivotal role in numerous biological processes, unambiguously in cancer biology they are best recognized by their ability to degrade basement membrane barriers, cleavage of structural components of the extracellular matrix as well as proteins that link cancer cells together. As such, the human "degradome", established by sequencing of the human genome show a great diversity among proteases, generating no less than 569 enzymes which are sub-divided to five subgroups: 194 metalloproteinases, and 176 serine, 150 cysteine, 28 threonine and 21 aspartic proteases [1,2]. Of note are enzymes involved in posttranslational degradation, for instance the deubiquitylases that regulate ubiquitine dependent signaling [3]. Deubiquitylases were recently put on stage, impacting critically on the Wnt/ $\beta$-catenin signaling path. The attachment of ubiquitine to a cell surface receptor marks it for internalization and degradation through the lysosomal system. For example, the zinc and ring finger 3 (Znrf3) and its homologue ring finger 43 (Rnf43); ZNRF3/RNF43, E3 ubiquitine ligases degrade cell surface frizzled (FZD) receptors and hence regulate the core pathway of Wnt/ $\beta$-catenin signaling, thereby keeping an adequate and balanced levels of FZDs under normal conditions $[4,5]$. Deubiquitylases that remove ubiquitine tagging lead to enhanced surface levels of FZDs and induced Wnt signaling in cancer, facilitating tumor growth. However, proteases not only cleave protein substrates, but are capable of sending cellular messages. This takes place by specifically activating cell surface receptors. It refers to serine proteases of the coagulation system that act as powerful "ligands" initiating the activation of protease-activated receptors (PARs), and instigate a selective signaling cascade. Both soluble and matrix-immobilized proteases anchored to the dynamic and flexible tumor microenvironment are engaged to maintain tumor growth and progression [6]. Indeed, a robust crosstalk between proteases and PARs takes place during epithelia tumor progression. PAR family members $\left(\mathrm{PAR}_{1-4}\right)$ belong to the large family of G-protein-coupled 
receptors (GPCRs). Although the growing appreciation of GPCRs in cancer pathogenesis is emerging, yet untill now, few drugs targeting GPCRs are used in cancer [7,8].

In this review, we will discuss our studies as also research work from other groups on the molecular mechanisms by which members of the coagulation pathway like thrombin, FVIIa and Xa activate GPCR and thereby induce tumor growth and angiogenesis [9-12]. In the first part we will illustrate how understanding the molecular mechanism of PAR signaling led to the development of PAR based drug discovery.

Large-scale genome-broad evaluations of numerous human tumors have revealed original alterations of GPCRs in cancer. These changes include copy number variations, mutations, methylation alterations and variable levels of gene expression observed in a wide range of cancers [13-15]. Yet, the task of establishing a tumor driver gene and therefore an effective drug target is nevertheless a tough challenge ahead. Technological advances in gene-sequencing and bioinformatics led to an explosion of information obtained by tumor biopsy specimen $[16,17]$. The wealth of information combined with ample gene variations, provide a glimpse to the intricacy of a tumor. Still the issue of how this can be translated to cancer therapeutics is a formidable, difficult task.

A gradual and stepwise approach should be taken. First, it is essential to determine a statistically significant GPCR driver-gene. Next, the selected GPCR must undergo biological testing in an appropriate cancer model system/s. One should keep in mind that genome analysis and the overwhelming flow of information may assist only in the first step, identifying a suitable gene candidate. Elucidation of the molecular pathway and flow of events by an individual or combined gene/s signaling are critical for establishing appropriate building blocks toward a successful intervention and the identification of additional targets for therapy.

The signaling network entails protein modules involved in intermolecular interactions. Among these, the pleckstrin homology (PH) domain is most common. $\mathrm{PH}$ domains are known by their structural features combined of an $\alpha$-helix at the C-terminus of the protein and a seven-stranded $\beta$-sandwich [18]. While their folding assembly show a common structural scaffold, $\mathrm{PH}$-domains are of no primary sequence homology. These modules serve as 'recognition-sites' acting to connect signal proteins by a specific code or message conveyed through the receptor. Lessons from a survey for the detection of candidates that can assemble with PAR family members, culminated with establishing particular motifs within the tails of PARs that can associate with the PH-domain of signal proteins. These binding motifs proved to be sufficient and critical for PAR based tumor development and therefore assigned as prevailing targets for therapy.

\section{1. $P A R_{1 \mathcal{E} 2}$ Associate with PH-Signal Proteins via 'Recognition Motifs' That Endow Junctional} Accesses to Cancer Growth

Both immunoprecipitation and pull-down assays over GST-fused $\mathrm{PAR}_{1}$ or $\mathrm{PAR}_{2}$ $\mathrm{C}$-tails have indicated the association with $\mathrm{Akt} / \mathrm{PKB}$, a serine/threonine protein kinase which plays a central role in tumor cell proliferation, survival and invasiveness $[19,20]$. This association was mediated via the PH-domain of Akt. Multiple signal proteins carry a PH-domain among of which are; Etk/Bmx, Akt, Vav, SOS1 and GAB1. Akt/PKB was chosen as a representative $\mathrm{PH}$-containing signal protein since Etk/Bmx is not expressed in certain cancer cell lines. The association of Akt with PARs is lipid dependent and generally referred to phosphatidylinositol $(3,4,5)$-trisphosphate (PtdIns(3,4,5)P3; PIP3) association with $\mathrm{PH}$-signal proteins. Nevertheless, PH-proteins may associate also in a lipid independent manner, directly via protein-protein interactions as was previously demonstrated for Etk/Bmx and Focal Adhesion Kinase (FAK) association [21]. This is also true for $\mathrm{PAR}_{1 \& 2}$ association with Etk/Bmx. Hence, PAR motifs can dynamically bind either directly to another protein or dependent on PIP3 lipid moiety, allowing a broader platform of interactions. The critical amino acids of the $\mathrm{PAR}_{2} \mathrm{PH}$-binding domain were determined by applying mutants H349A and R352A. It appears that there is a hierarchy for the binding of $\mathrm{PAR}_{2} \mathrm{C}$-tail to PH-signal proteins. While PH-Etk/Bmx, PH-Akt and $\mathrm{PH}-\mathrm{Vav} 3$ bind to the same region of $\mathrm{PAR}_{2}-\mathrm{PH}$ binding motifs, lysates applied on either 
GST-PH-Etk/BMX, GST-PH-Akt columns have indicated the following outcome. Cancer cell-lines that express endogenously Etk/Bmx preferentially associate with the C-tails of $\mathrm{PAR}_{1 \& 2}$. Only in cell lines lacking Etk/BMX the tight association between PAR $1 \& 2$ and Akt is seen [20]. The nature of Etk/Bmx association with $\mathrm{PAR}_{2}$ was shown by application of various constructs of $e t k / b m x$. When a plasmid in which the PH domain of Etk/Bmx was deleted and replaced by myristoyl group termed $\mathrm{Myr}-\mathrm{dPH}$ or a construct composed of SH2, SH3 and the kinase domain named; TH-SH2-SH3-KD were evaluated for the binding with $\mathrm{PAR}_{2}$, no association was observed with either constructs. In-contrast, a tight association is seen with the wt Etk/Bmx. In-addition, application of the PI3K inhibitor; LY294002 did not abrogate association of $\mathrm{PAR}_{2}$ with Etk/Bmx, however it markedly attenuated the association of $\mathrm{PAR}_{2}$ with Akt. Altogether these results show unequivocally a lipidindependent association of the Etk/Bmx PH-domain with $\mathrm{PAR}_{2}$.

\subsection{Tumor Growth, In Vivo}

The use of a xenograft mouse model was employed in order to demonstrate the significance of PH-binding motifs in PAR driven tumors. For this purpose, stable clones expressing either wt Par2, truncated Par2 (devoid of the entire cytoplasmic tail), MutPar2 H349A or MutPar2 R352A clones were generated in HU fibrocystic epithelial cells. When these stable clones were inoculated s.c. into nude mice the results obtained showed the importance of $\mathrm{PAR}_{2} \mathrm{PH}$-binding motif in tumor growth. While large tumors were seen following inoculation of cells overexpressing wt Par2, in-contrast very small tumors were observed in the control HU cell injected as well as following injections of cells exhibiting the truncated form of Par2 (e.g., incapable of eliciting PAR driven signaling). Inhibition in tumor growth was obtained as well by the implantation of a clone of MutPar2 H349A. Tumor measurements of weight and volume as well as by the evaluation of the intensities of the GFP expressed in these tumors, aided to conclude the observed outcome. It is determined that the PH-binding motifs are pivotal for tumor growth in PAR- mediated cancer (Figure 1). PARs are overexpressed in a wide spectrum of epithelial malignancies as opposed to no PAR expression in normal epithelial cells. A partial list of epithelial malignancies include breast-, colon, prostate, lung- and ovarian cancers. We have demonstrated that knocking down of $\mathrm{PAR}_{1}$ and/or $\mathrm{PAR}_{2}$ expression resulted with significant reduction in breast and prostate tumor growth. It is anticipated that a PAR based therapy will contribute greatly to a wide range of epithelial derived solid tumors. We as also others have demonstrated the overexpression of $\mathrm{PAR}_{1}$ for example in prostate cancer [22,23] as also in breast cancer [20].

\subsection{Placenta-EVT Invasion Is Enhanced via $P A R_{2}-P H$ Binding Domain}

Human pregnancy entails the early-on and well-orchestrated anchorage of the placenta to the uterus decidua. This is mediated by specialized cells called extravillous trophoblasts (EVT). Placenta establishment to the uterus involves the time-limited invasion process which is shut-off thereafter and therefore referred to as a 'physiological invasion' process. The importance of $\mathrm{PAR}_{1 \& 2} \mathrm{PH}$ binding domains in physiological invasion process was demonstrated by an in vitro model based on villi invasion, isolated from early placenta gestation (7-12 weeks of pregnancy). These villi were infected with lentil virus of either wt hPar1, mutant $h$ Par1 $7 \mathrm{~A}$ (mutated in the entire PAR $_{1}$ PH-binding domain), wt hPar2 or hPar $2 \mathrm{H} 349 \mathrm{~A}$ and activated with TFLLR (for PAR ) or SLIGKV $\left(\mathrm{PAR}_{2}\right)$. Next, the depth of EVT invasion through a Matrigel layer was estimated [15]. While the wt constructs showed increased level of invasion with high proliferation rate as indicated by $k i 67$, the mutated PH-binding motif constructs significantly attenuated invasion and proliferation. Hence the $\mathrm{PAR}_{1 \& 2} \mathrm{PH}$-binding motifs are essential also for the 'physiological invasion' process. 


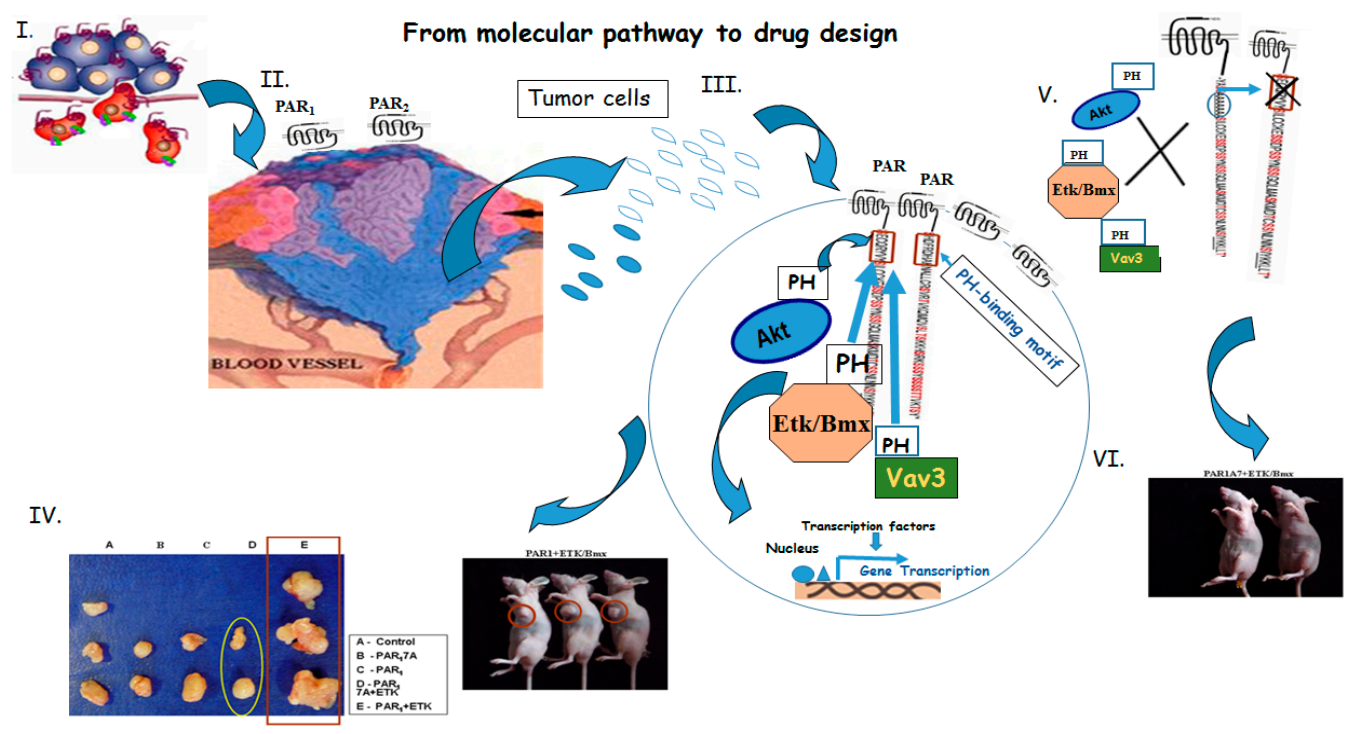

Figure 1. From molecular pathway to drug design. I. Scheme of epithelial cells invading basement membrane. II. Scheme of tumor cells that invaded the basement membrane and are spreading via the vascular system. III. The subfamily of GPCRs; PAR oncogenes display a PH-binding domain within their cytoplasmic C-tails. Signal proteins that possess PH-domain such as; Akt, Etk/Bmx and Vav3 can associate with PAR C-tails initiating thereby a tumor signaling cascade. IV. PAR-derived tumors are generated upon the inoculation of cells overexpressing $\mathrm{PAR}_{1}$ (or $\mathrm{PAR}_{2}$ ) in the mouse fourth mammary gland. V. Application of an inhibitor of the PAR PH-binding domain, effectively abrogates PH-signal protein association with PARs. VI. In the presence of the PH-binding site inhibitor, no to nearly very small tumors are developed.

\section{4. $P A R_{2}$ Is Dominant over $P A R_{1}$}

We as well as others $[24,25]$ have shown that $\mathrm{PAR}_{2}$ takes a dominant role over $\mathrm{PAR}_{1}$ as recapitulated by the essential presence of $\mathrm{PAR}_{2}$ for $\mathrm{PAR}_{1}$ induced pro-tumor functions. Accordingly, when shRNA silenced $h$ Par 2 was applied, a marked inhibition of $\mathrm{PAR}_{1}$ induced function was seen. Consequently, it appears that the signaling by $\mathrm{PAR}_{2}$ is pivotal for $\mathrm{PAR}_{1}$ function since a truncated form of PAR 2 devoid of the C-tail, markedly inhibited PAR 1 induced activities as manifested by colony formation in soft agar, migration and invasion. Co-association between $\mathrm{PAR}_{1}-\mathrm{PAR}_{2}$ is demonstrated by co-IP and confocal analyses indicating the colocalization of $\mathrm{PAR}_{1}$ with $\mathrm{PAR}_{2}$. This is true also for PAR induced physiological invasion of placenta to the uterus decidua. shRNA $h$ Par2 significantly inhibited in an organ culture system, the thrombin-activated EVT invasion. Hence, $\mathrm{PAR}_{2}$ is also required for $\mathrm{PAR}_{1}$ induced EVT invasion. This can be partially explained by the formation of one functional unit entailing $\mathrm{PAR}_{1}-\mathrm{PAR}_{2}$, in PAR-driven invasion, regardless of physiological or pathological invasion process [24,25].

\subsection{A Lead Cyclic Peptide Directed toward the PAR 2 PH-Binding Domain}

The FDA has approved several cyclic peptide drugs, out of which three; pasireotide, romidepsin and lanreotide are used in cancer. While lanreotide and pasireotide are analogues of the endogenous cyclic peptide hormone somatostatin [26], romidepsin is in-fact a natural product generated from a gram-negative Chromabacterium violaceum and was found useful in T-cell lymphoma [27]. Somatostatin blocks the GPCR somatostatin receptors. These cyclic peptide mimetics have a considerably longer plasma half-life than somatostatin and are utilized to treat endocrine tumors and acromegaly. It is anticipated that a selected cyclic peptide directed toward $\mathrm{PAR}_{2} \mathrm{PH}$-binding motif may pave the way to successfully treat solid epithelia malignancies by blocking directly GPCR/PARs as well as possibly inhibiting other signaling network that bypasses and cross-talks with PARs. 
Methodology that uses cyclic peptides is valuable and display favorable outcome in treatment. This is ascribed to several favorable properties. First, cyclic peptides possess a large surface region that offers high selectivity and affinity for directed proteins. Second, they constitute little to no toxicity owing to their mild amino acid make-up. Third, cyclic peptides are straightforward to prepare (by automated synthesis), and are pretty easy to handle, alter, and describe, all of which are important properties for therapeutics [28]. Backbone-cyclized peptides and peptidomimetics join to provide an efficient tool combined with pharmacological features and are required for working research implements and therapeutics. Backbone cyclization is a technique that allows the development of cyclic peptides without using amino-acids common to the natural linear peptide, which may be critical for the peptide biological activity, mainly if the peptide is short. The main advantage of this procedure is that the cyclization linkage is formed between backbone atoms, without the side chain active group atoms, which are vital for the peptide link and biological function. This arrangement keeps the regular residue functional groups in their bioactive conformation necessary for drug-like features. A cyclic peptide frequently mimics the protein secondary arrangement and displays sustained and longer stability. Optimization of peptide cyclization usually takes place in terms of ring size and in the field of cancer research for longstanding effects on reducing tumor growth in mice.

\subsection{Identification of Candidates PH-Domain Binding Motifs in a GPCR Array}

In order to allocate powerful cancer therapeutic target sites within candidate GPCRs, it is suggested to isolate the $\mathrm{PH}$-domain of Akt, as a representative of signal protein $\mathrm{PH}$-domains. The PH-domain of Akt and/or Etk/Bmx when sub cloned into a bacteria expression vector pParallel 2-HL T vector between EcoR1 and BamH1 sites enables overexpression of the recombinant DNA inserted. The soluble PH-binding domain can be then tagged with a GFP tag. Next, preparation of an array of GPCR C-tails embedded filter is the best option for filter preparation and a way to minimize loss of secondary structures. Hybridization following application of the GFP tagged-PH-Akt domain alone is intended to allocate PH-binding 'recognition-sites' for cancer therapeutic purposes (Scheme 1). This approach will nonetheless assist in finding additional drug targets within GPCRs.

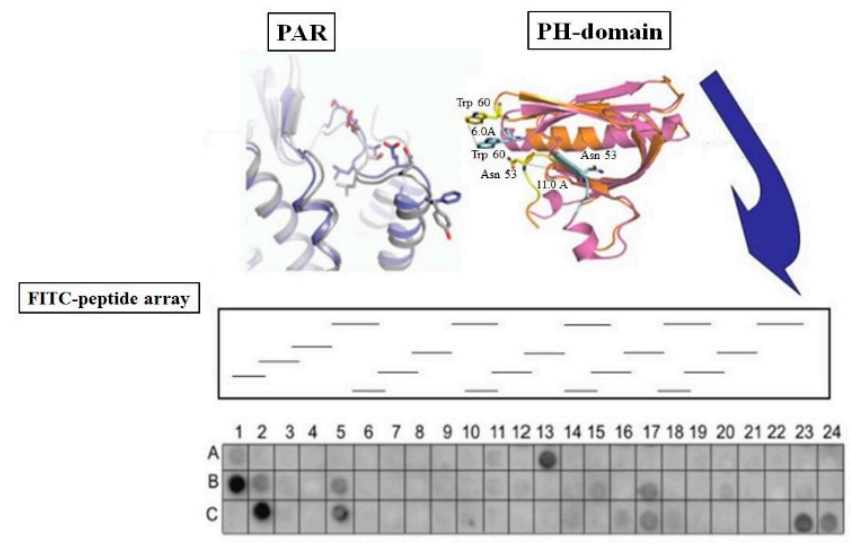

Scheme 1. A strategy depicting detection of GPCR PH-binding domain. Application of the purified Akt PH-domain onto an array membrane of cancer driver GPCRs. Scheme of blood vessel. GPCRs expressed in the endothelial cell lining, coagulation factors in the tumor microenvironment. GPCR mediated secretion of angiogenic factors.

\subsection{Tumor Angiogenesis}

To obtain improved delivery of chemotherapy for the gain of tumor shrinkage, fewer metastases and increased survival time, is yet a tough challenge. Delivery is mediated by the blood vessel network. Keeping in mind that antiangiogenic treatments have not generated extensive clinical benefits, point to the fact that aggressive anti angiogenic strategies and drastic reduction in tumor blood vessels should be re-evaluated. The 
formation of new blood vessels (vasculogenesis and angiogenesis) includes coordinated functions of endothelial cell migration, proliferation, and tube alignment. Since tumors are limited in size by nutrient diffusion and oxygen supply from neighboring vessels, a wide spectrum of solid tumors are heavily dependent on their vascularization [29-32]. Certainly, angiogenesis; the growth of blood vessels from pre-existing vessels is the main reason for the flourishing of a tumor, therefore it calls for vessel elimination. On the other hand, drastic reduction of blood vessels impairs proper drug delivery and hence should be carefully monitored. Studies from the lab of Hodivala-Dilke have demonstrated the efficacy of low-dose Cilengitide, a cyclic peptide mimetic of an integrin-specific RGD directed to $\alpha v \beta 3 / \alpha v \beta 5$, can markedly improve tumor treatment and stands in-contrast to high-dose Cilengitide. The best outcome was achieved by combination therapy that include low-dose Cilengitide along with Verapamil and the chemotherapy Gemcitabine [33]. This outcome put forward the notion favoring "vascular promotion" for therapeutic purposes. Functional blood vessels must undergo endothelial cell proliferation initiated by Vascular Endothelial Growth Factor (VEGF) and basic Fibroblast Growth Factor (FGF-2; bFGF) which are primary mediators of blood vessels, significantly upregulated in the vicinity of a tumor [31,32]. The appearance of new blood vessels from preexisting one is affected by the growth factor receptors KDR/flk-1 and flt-1 and by a spectrum of adhesion molecules, primarily integrins $[32,34,35]$.

The pivotal involvement of GPCRs in angiogenesis was demonstrated via G $\alpha 13^{-/-}$ $\mathrm{KO}$ mice [36] resulting with mouse embryo lethality. G-proteins are known to play a central part in the cell signaling of GPCRs. Interruption of the gene that encodes G $\alpha 13$ compromises the ability to generate and build the vascular endothelial system and therefore causes intrauterine embryonal death.

Several GPCRs have been shown as critically impacting on angiogenesis $[37,38]$. For example, frizzled receptors (FZDs); a GPCR subfamily of the Wnt ligands, are known for governing among others, embryonic stem cell development, pathological malignancies. FZDs 4, 6, 7 and 8 are involved in the development of blood vessels from progenitor embryonic stem cells [39-41]. Other GPCRs are best known in participating via the upregulation of VEGF and bFGF. As such are: sphingosine 1P receptor; S1P1) [42-44], CXCR4 [45-48] and $\mathrm{PAR}_{1}[49]$.

Exclusive disruption of the S1P1 gene by the Cre/Lox methodology, in the ECs resulted in mouse embryonic lethality. It was demonstrated that the embryonic blood vessels were only partly covered by vascular smooth muscle cells (VSMCs), indicating that S1P1 receptor is critical for vascular maturation [42]. Endothelial differentiation gene; Edg1 $1^{-/}$ $\mathrm{KO}$ (another name for S1P1) mice showed embryonic hemorrhage and consequently intrauterine death between day E12.5 and E14.5 [50]. S1P1 induces also human vascular (HUVEC) as also bovine aortic vascular endothelial cell (BAVEC) migration, impacting on adult angiogenesis, as well [51].

Studies from our lab have demonstrated that $\mathrm{PAR}_{1}$ plays a significant role in the recruitment of blood vessels in vivo using the "Matrigel plug" assay in mice. Par1 gene recruits effectively blood vessels as shown in animal models. By in vivo injection of Matrigel plugs containing rat prostatic carcinoma cells transfected with the tetracycline-inducible Par1 an increased angiogenesis and the appearance of reddish Matrigel plugs was observed upon the conditional induced overexpression of Par1 (Figure 2). It is shown that Par1 enhances all four splice forms of VEGF, mediated by the signaling events involving PKC, src and PI3K. Functional VEGF was recapitulated by the formation of human endothelial tube network as also bovine aortic endothelial cell proliferation. Oncogene upregulation of Ras, Src and Vav in Par1 induced VEGF was seen [49]. In this regard, application of a cyclic peptide directed towards the PH-binding domain of PAR may prove beneficial in the combat of PAR induced VEGF mediated angiogenesis. 


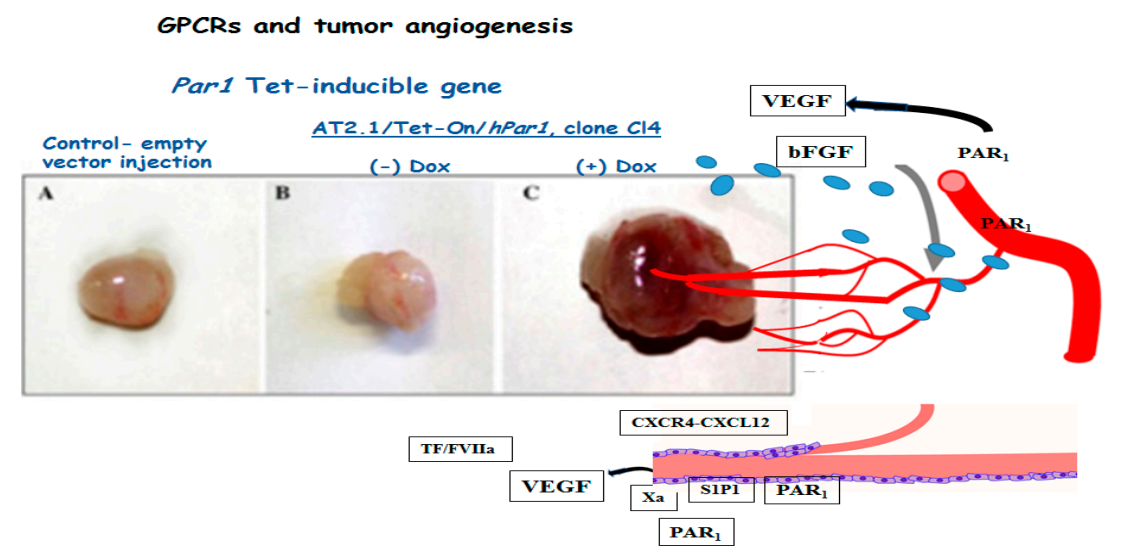

Figure 2. Inducible Par1 expression in rat prostatic carcinoma increases tumor mass and angiogenesis. AT2.1/Tet-On/hPar1 clone Cl4 cells and control transfected (A) (vector only) cells were injected into rats, subcutaneously. Animals were maintained for 2 weeks with regular drinking water (B) or drinking water supplemented with Dox $(\mathbf{A}, \mathbf{C})$. After 2 weeks, tumors were excised and evaluated for weight and color. Tumors shown were from animals injected with the following: (A) control transfected cells, nourished with Dox for 2 weeks; (B) AT2.1/Tet-On/hPar1, clone C14; (C) AT2.1/TetOn/hPar1 clone $\mathrm{Cl} 4$, nourished with Dox for 2 weeks.

Along this line of evidence, the group of A. Malik revealed that Par1 is an essential gene for mouse embryonic stem cell (mESC) differentiation step from progenitor undifferentiated cell status culminating with the formation of blood vessels. This was concluded from an expression profile analysis of GPCRs in mESCs and mESC-derived ECs. In the presence of $\mathrm{PAR}_{1}$ differentiation of mESCs to ECs and ultimately the generation of functional blood vessels took place. In-contrast, this differentiation was attenuated upon the depletion of Par1 [52]. Indeed, studies on $\mathrm{PAR}_{1}{ }^{-/} \mathrm{KO}$ mice have indicated lethality of $~ 50 \%$ in mouse embryos as a result of impaired vasculogenesis [53]. This outcome is in-line and compatible also with $\mathrm{G} \alpha 13^{-/-}$mouse embryos that are lethal, similar to Par1 KO embryos [36].

Chemokines and their receptors, principally the chemokine (C-X-C motif) ligand 12 (CXCL12) and its receptor CXCR4, have gained attention for their functional roles as being able to communicate between tumor cells and the tumor microenvironment including immune and vascular cells as also the stroma. They are involved in leukocyte trafficking and numerous pathological conditions. A shared feature in solid tumors and a critical microenvironmental instigator is hypoxia which effectively initiates behavior of aggressive cancers. Under hypoxia, the enhanced overexpression of VEGF [54] is observed as well as the marked upregulation of CXCR4 [55]. This is mediated in a HIF- $1 \alpha$-dependent manner since blocking of HIF- $1 \alpha$ attenuated hypoxia induced CXCR4 upregulation. The axis of CXCR4/CXCL12 in angiogenesis is involved in the activation of endothelial progenitor cells as also recruitment of factors such as VEGF [54]. CXCL12 and its receptor enables a permissive microenvironment for angiogenesis, since it has been demonstrated that cancer associated fibroblast inoculated in breast cancer caused enhanced tumor growth and development as compared to normal fibroblasts. This was attributed to the ability of cancer associated fibroblasts to trigger tumor angiogenesis through the recruitment of endothelial progenitor cells facilitated by CXCL12 [56]. The CXCR4 antagonist AMD3100 prevented the ability of CXCL12 to induce high vasculature in glioma by preventing endothelial progenitor cell fusion [57]. Moreover, it is interesting to note that there is a difference between vasculature of breast cancer induced by either Her2 ${ }^{+}$where anti CXCL12 agents are not effective in contrast to Wnt1 derived tumors. Histological evaluations showed that in MMTV-Wnt1 tumors high levels of epithelial or stromal CXCL12 is observed and therefore anti CXCL12 neutralizing abs effectively inhibited breast cancer derived from MMTV-Wnt1 but not Her2 induced breast cancer [58]. 
In conclusion, ample examples of GPCR involvement in tumor angiogenesis and cancer lead to the realization that regulated management of GPCRs and their signaling events may centrally contribute in the combat of cancer.

Author Contributions: Conceptualization, R.B.-S.; methodology, J.K.N., H.M., S.S. and P.A.; software, J.K.N., S.S. and P.A.; validation, J.K.N.; writing—original draft preparation, R.B.-S.; writing-review and editing, R.B.-S.; project administration, R.B.-S.; funding acquisition, R.B.-S. All authors have read and agreed to the published version of the manuscript.

Funding: This research was funded by the Israel Science Foundation no. 1420/16.

Institutional Review Board Statement: Animals studies were carried out in accordance with the guidelines of the Hebrew University ethics committee (AAALAC standard). Approval No. MD-2015924-5.

Informed Consent Statement: No human subjects were involved in this study.

Acknowledgments: This work is supported by the Israel Science Foundation grant 1420/16 and Kamin Program by the Israel Innovation Authority to Bar-Shavit R.

Conflicts of Interest: No conflict of interest.

$\begin{array}{ll}\text { Abbreviations } \\ \text { GPCRs } & \text { G-protein coupled receptors } \\ \text { PARs } & \text { protease-activated receptors } \\ \text { Znrf3 } & \text { zinc and ring finger 3 } \\ \text { Rnf43 } & \text { ring finger protein 43 } \\ \text { FZD } & \text { Frizzled } \\ \text { PH } & \text { domain-pleckstrin homology domain } \\ \text { FAK } & \text { focal adhesion kinase } \\ \text { Gab1-Grb2 } & \text { associated binder 1 } \\ \text { Sos } & \text { Son of Sevenless } \\ \text { EVT } & \text { extravillous trophoblasts } \\ \text { VEGF } & \text { vascular endothelial growth factor } \\ \text { bFGF } & \text { basic Fibroblast Growth Factor } \\ \text { mESC } & \text { mouse embryonic stem cell } \\ \text { S1P1 } & \text { Sphingosine-1-phosphate receptor 1 }\end{array}$

\section{References}

1. López-Otín, C.; Matrisian, L.M. Emerging roles of proteases in tumour suppression. Nat. Rev. Cancer 2007, 7, 800-808. [CrossRef]

2. Dudani, J.S.; Warren, A.D.; Bhatia, S.N. Harnessing Protease Activity to Improve Cancer Care. Annu. Rev. Cancer Biol. 2017, 23, 353-376. [CrossRef]

3. Hoeller, D.; Hecker, C.M.; Dikic, I. Ubiquitin and ubiquitin-like proteins in cancer pathogenesis. Nat. Rev. Cancer 2006, 6, 776-788. [CrossRef] [PubMed]

4. Hao, H.X.; Xie, Y.; Zhang, Y.; Charlat, O.; Oster, E.; Avello, M.; Lei, H.; Mickanin, C.; Liu, D.; Ruffner, H.; et al. ZNRF3 promotes Wnt receptor turnover in an R-spondin-sensitive manner. Nature 2012, 485, 195-200. [CrossRef] [PubMed]

5. Koo, B.-K.; Spit, M.; Jordens, I.; Low, T.Y.; Stange, D.E.; van de Wetering, M.; van Es, J.H.; Mohammed, S.; Heck, A.J.R.; Maurice, M.M.; et al. Tumour suppressor RNF43 is a stem-cell E3 ligase that induces endocytosis of Wnt receptors. Nature 2012, 488, 665-669. [CrossRef] [PubMed]

6. Steeg, P.S. Tumor metastasis: Mechanistic insights and clinical challenges. Nat. Med. 2006, 12, 895-904. [CrossRef]

7. Coughlin, S.R. Thrombin signalling and protease-activated receptors. Nature 2000, 407, 258-264. [CrossRef]

8. Gutkind, J.S.; Kostenis, E. Arrestins as rheostats of GPCR signalling. Nat. Rev. Mol. Cell Biol. 2018, 19, 615-616. [CrossRef]

9. Roy, A.; Ansari, S.A.; Das, K.; Prasad, R.; Bhattacharya, A.; Mallik, S.; Mukherjee, A.; Sen, P. Coagulation factor VIIa-mediated protease-activated receptor 2 activation leads to $\beta$-catenin accumulation via the AKT/GSK3 $\beta$ pathway and contributes to breast cancer progression. J. Biol. Chem. 2017, 292, 13688-13701. [CrossRef]

10. Morris, D.R.; Ding, Y.; Ricks, T.K.; Gullapalli, A.; Wolfe, B.L.; Trejo, J. Protease-activated receptor-2 is essential for factor VIIa and Xa-induced signaling, migration, and invasion of breast cancer cells. Cancer Res. 2006, 66, 307-314. [CrossRef] [PubMed]

11. Nierodzik, M.L.; Karpatkin, S. Thrombin induces tumor growth, metastasis, and angiogenesis: Evidence for a thrombin-regulated dormant tumor phenotype. Cancer Cell 2006, 10, 355-362. [CrossRef] [PubMed] 
12. Even-Ram, S.; Uziely, B.; Cohen, P.; Grisaru-Granovsky, S.; Maoz, M.; Ginzburg, Y.; Reich, R.; Vlodavsky, I.; Bar-Shavit, R. Thrombin receptor overexpression in malignant and physiological invasion processes. Nat. Med. 1998, 4, 909-914. [CrossRef]

13. Kan, Z.; Jaiswal, B.S.; Stinson, J.; Janakiraman, V.; Bhatt, D.; Stern, H.M.; Yue, P.; Haverty, P.M.; Bourgon, R.; Zheng, J.; et al. Diverse somatic mutation patterns and pathway alterations in human cancers. Nature 2010, 466, 869-873. [CrossRef] [PubMed]

14. Hammerman, P.S.; Hayes, D.N.; Wilkerson, M.D.; Schultz, N.; Bose, R.; Chu, A.; Collisson, E.A.; Cope, L.; Creighton, C.J.; Getz, G.; et al. Comprehensive genomic characterization of squamous cell lung cancers. Nature 2012, 489, 519-525.

15. De Carvalho, D.D.; Sharma, S.; You, J.S.; Su, S.F.; Taberlay, P.C.; Kelly, T.K.; Yang, X.; Liang, G.; Jones, P.A. DNA methylation screening identifies driver epigenetic events of cancer cell survival. Cancer Cell 2012, 21, 655-667. [CrossRef] [PubMed]

16. Garraway, L.A.; Lander, E.S. Lessons from the cancer genome. Cell 2013, 153, 17-37. [CrossRef]

17. O'Hayre, M.; Vazquez-Prado, J.; Kufareva, I.; Stawiski, E.W.; Handel, T.M.; Seshagiri, S.; Gutkind, J.S. The emerging mutational landscape of G-proteins and G-protein-coupled receptors in cancer. Nat. Rev. Cancer 2013, 13, 412-424. [CrossRef]

18. Lemmon, M.A.; Ferguson, K.M. Signal-dependent membrane targeting bypleckstrin homology (PH) domains. Biochem. J. 2000, 350, 1-18. [CrossRef]

19. Hanada, M.; Feng, J.; Hemmings, B.A. Structure, regulation and function of PKB/AKT-a major therapeutic target. Biochim. Biophys. Acta 2004, 1697, 3-16. [CrossRef]

20. Kancharla, A.; Maoz, M.; Jaber, M.; Agranovich, D.; Peretz, T.; Grisaru-Granovsky, S.; Uziely, B.; Bar-Shavit, R. PH motifs in PAR1\&2 endow breast cancer growth. Nat. Commun. 2015, 6, 8853-8864.

21. Chen, R.; Kim, O.; Li, M.; Xiong, X.; Guan, J.L.; Kung, H.J.; Chen, H.; Shimizu, Y.; Qiu, Y. Regulation of the PH-domain-containing tyrosine kinase Etk by focal adhesion kinase through the FERM domain. Nat. Cell Biol. 2001, 3, 439-444. [CrossRef] [PubMed]

22. Shi, X.; Gangadharan, B.; Brass, L.F.; Ruf, W.; Mueller, B.M. Protease-activated receptors (PAR1 and PAR2) contribute to tumor cell motility and metastasis. Mol. Cancer Res. 2004, 2, 395-402. [PubMed]

23. Salah, Z.; Maoz, M.; Cohen, I.; Pizov, G.; Pode, D.; Runge, M.S.; Bar-Shavit, R. Identification of a novel functional androgen response element within hPar1 promoter: Implications to prostate cancer progression. FASEB J. 2005, 19, 62-72. [CrossRef] [PubMed]

24. Sevigny, L.M.; Austin, K.M.; Zhang, P.; Kasuda, S.; Koukos, G.; Sharifi, S.; Covic, L.; Kuliopulos, A. Protease-activated receptor-2 modulates protease-activated receptor-1-driven neointimal hyperplasia. Arterioscler. Thromb. Vasc. Biol. 2011, 31, e100-e106. [CrossRef]

25. Jaber, M.; Maoz, M.; Kancharla, A.; Agranovich, D.; Peretz, T.; Grisaru-Granovsky, S.; Uziely, B.; Bar-Shavit, R. Protease-activatedreceptor-2 affects protease-activatedreceptor-1-driven breast cancer. Cell Mol. Life Sci. 2014, 71, 2517-2533. [CrossRef]

26. Modlin, I.M.; Pavel, M.; Kidd, M.; Gustafsson, B.I. Somatostatin analogues in the treatment of gastroenteropancreatic neuroendocrin (carcinoid) tumours. Aliment. Pharmacol. Ther. 2010, 31, 169-188.

27. Jain, S.; Zain, J. Romidepsin in the treatment of cutaneous T-cell lymphoma. J. Blood Med. 2011, 2, 37-47.

28. Zorzi, A.; Deyle, K.; Heinis, C. Cyclic peptide therapeutics: Past, present and future. Curr. Opin. Chem. Biol. 2017, 38, 24-29. [CrossRef]

29. Bergers, G.; Javaherian, K.; Lo, K.M.; Folkman, J.; Hanahan, D. Effects of angiogenesis inhibitors on multistage carcinogenesis in mice. Science 1999, 284, 808-812. [CrossRef] [PubMed]

30. Folkman, J. Tumor angiogenesis: Therapeutic implications. N. Engl. J. Med. 1971, 285, 1182-1186. [PubMed]

31. Ferrara, N.; Carver-Moore, K.; Chen, H.; Dowd, M.; Lu, L.; O'Shea, K.S.; Powell-Braxton, L.; Hillan, K.J.; Moore, M.W. Heterozygous embryonic lethality induced by targeted inactivation of the VEGF gene. Nature 1996, 380, 439-442. [CrossRef]

32. Ferrara, N.; Alitalo, K. Clinical applications of angiogenic growth factors and their inhibitors. Nat. Med. 1999, 5, 1359-1364. [CrossRef]

33. Wong, P.-P.; Demircioglu, F.; Ghazaly, E.; Alrawashdeh, W.; Stratford, M.R.L.; Scudamore, C.L.; Cereser, B.; Crnogorac, J.T.; McDonald, S.; Elia, G.; et al. Dual-Action Combination Therapy Enhances Angiogenesis while Reducing Tumor Growth and Spread. Cancer Cell 2015, 27, 123-137. [CrossRef] [PubMed]

34. Hynes, R.O.; Bader, B.L.; Hodivala-Dilke, K. Integrins in vascular development. Braz. J. Med. Biol. Res. 1999, 32, 501-510. [CrossRef] [PubMed]

35. Hanahan, D.; Folkman, J. Pattern and emerging mechanisms of angiogenic switch during tumorigenesis. Cell 1996, 86, 353-364. [CrossRef]

36. Offermanns, S.; Mancino, V.; Revel, J.P.; Simon, M.I. Vascular system defects and impaired cell chemokinesis as a result of Galpha13 deficiency. Science 1997, 275, 533-536. [CrossRef] [PubMed]

37. Richard, D.E.; Vouret-Craviari, V.; Pouysségur, J. Angiogenesis and G-protein-coupled receptors: Signals that bridge the gap. Oncogene 2001, 20, 1556-1562. [CrossRef] [PubMed]

38. De Francesco, E.M.; Sotgia, F.; Clarke, R.B.; Lisanti, M.P.; Maggiolini, M.G. Protein-Coupled Receptors at the Crossroad between Physiologic and Pathologic Angiogenesis: Old Paradigms and Emerging Concepts. Int. J. Mol. Sci. 2017, 18, 2713. [CrossRef] [PubMed]

39. Klein, D.; Demory, A.; Peyre, F.; Kroll, J.; Augustin, H.G.; Helfrich, W.; Kzhyshkowska, J.; Schledzewski, K.; Arnold, B.; Goerdt, S. Wnt2 acts as a cell type-specific, autocrine growth factor in rat hepatic sinusoidal endothelial cells cross-stimulating the VEGF pathway. Hepatology 2008, 47, 1018-1031. [CrossRef] [PubMed] 
40. Liebner, S.; Corada, M.; Bangsow, T.; Babbage, J.; Taddei, A.; Czupalla, C.J.; Reis, M.; Felici, A.; Wolburg, H.; Fruttiger, M. Wnt/beta-catenin signaling controls development of the blood-brain barrier. J. Cell Biol. 2008, 183, 409-417. [CrossRef]

41. Barcelos, L.S.; Duplaa, C.; Kränkel, N.; Graiani, G.; Invernici, G.; Katare, R.; Siragusa, M.; Meloni, M.; Campesi, I.; Monica, M.; et al . Human CD133+ progenitor cells promote the healing of diabetic ischemic ulcers by paracrine stimulation of angiogenesis and activation of Wnt signaling. Circ. Res. 2009, 104, 1095-1102. [CrossRef]

42. Allende, M.L.; Yamashita, T.; Proia, R.L. G-protein-coupled receptor S1P1 acts within endothelial cells to regulate vascular maturation. Blood 2003, 102, 3665-3667. [CrossRef]

43. Lee, M.J.; Thangada, S.; Claffey, K.P.; Ancellin, N.; Liu, C.H.; Kluk, M.; Volpi, M.; Sha'afi, R.I.; Hla, T. Vascular endothelial cell adherens junction assembly and morphogenesis induced by sphingosine-1-phosphate. Cell 1999, 99, 301-312. [CrossRef]

44. Garcia, J.G.; Liu, F.; Verin, A.D.; Birukova, A.; Dechert, M.A.; Gerthoffer, W.T.; Bamberg, J.R.; English, D. Sphingosine 1-phosphate promotes endothelial cell barrier integrity by Edg-dependent cytoskeletal rearrangement. J. Clin. Investig. 2001, 108, 689-701. [CrossRef] [PubMed]

45. Xue, L.J.; Mao, X.B.; Ren, L.L.; Chum, X.Y. Inhibition of CXCL12/CXCR4 axis as a potential targeted therapy of advanced gastric carcinoma. Cancer Med. 2017, 6, 1424-1436. [CrossRef]

46. Chen, Q.; Zhong, T. The association of CXCR4 expression with clinicopathological significance and potential drug target in prostate cancer: A meta-analysis and literature review. Drug Des. Dev. Ther. 2015, 9, 5115-5122. [CrossRef] [PubMed]

47. Rupertus, K.; Sinistra, J.; Scheuer, C.; Nickels, R.M.; Schilling, M.K.; Menger, M.D.; Kollmar, O. Interaction of the chemokines I-TAC (CXCL11) and SDF-1 (CXCL12) in the regulation of tumor angiogenesis of colorectal cancer. Clin. Exp. Metastasis 2014, 31, 447-459. [CrossRef]

48. Ping, Y.F.; Yao, X.H.; Jiang, J.Y.; Zhao, L.T.; Yu, S.C.; Jiang, T.; Lin, M.C.; Chen, J.H.; Wang, B.; Zhang, R.; et al. The chemokine CXCL12 and its receptor CXCR4 promote glioma stem cell-mediated VEGF production and tumour angiogenesis via PI3K/AKT signalling. J. Pathol. 2011, 224, 344-354. [CrossRef] [PubMed]

49. Yin, Y.J.; Salah, Z.; Maoz, M.; Even Ram, S.C.; Ochayon, S.; Neufeld, G.; Katzav, S.; Bar-Shavit, R. Oncogenic transformation induces tumor angiogenesis: A role for PAR1 activation. FASEB J. 2005, 17, 163-174. [CrossRef]

50. Liu, Y.; Wada, R.; Yamashita, T.; Mi, Y.; Deng, C.X.; Hobson, J.P.; Rosenfeldt, H.M.; Nava, V.E.; Chae, S.S.; Lee, M.J.; et al. Edg-1, the $\mathrm{G}$ protein-coupled receptor for sphingosine-1-phosphate, is essential for vascular maturation. J. Clin. Investig. 2000, 106, 951-961. [CrossRef]

51. Wang, F.; Van Brocklyn, J.R.; Hobson, J.P.; Movafagh, S.; Zukowska-Grojec, Z.; Milstien, S.; Spiegel, S. Sphingosine 1-phosphate stimulates cell migration through a G(i)-coupled cell surface receptor. Potential involvement in angiogenesis. J. Biol. Chem. 1999, 274, 35343-35350. [CrossRef]

52. Gong, H.; An, S.; Sassmann, A.; Liu, M.; Mastej, V.; Mittal, M.; Zhang, W.; Hong, Z.; Offermanns, S.; Rehman, J.; et al. PAR1 Scaffolds TGFbRII to Downregulate TGF-b Signaling and Activate ESC Differentiation to Endothelial Cells. Stem Cell Rep. 2016, 7, 1050-1058. [CrossRef]

53. Griffin, C.T.; Srinivasan, Y.; Zheng, Y.W.; Huang, W.; Coughlin, S.R. A role for thrombin receptor signaling in endothelial cells during embryonic development. Science 2001, 293, 1666-1670. [CrossRef]

54. Shweiki, D.; Itin, A.; Soffer, D.; Keshet, E. Vascular endothelial growth factor induced by hypoxia may mediate hypoxia-initiated angiogenesis. Nature 1992, 359, 843-845. [CrossRef] [PubMed]

55. Oh, Y.S.; Kim, H.Y.; Song, I.-C.; Yun, H.-J.; Jo, D.-Y.; Kim, S.; Lee, H.J. Hypoxia induces CXCR4 expression and biological activity in gastric cancer cells through activation of hypoxia-inducible factor-1 $\alpha$. Oncol. Rep. 2012, 28, 2239-2246. [CrossRef]

56. Orimo, A.; Gupta, P.B.; Sgroi, D.C.; Arenzana-Seisdedos, F.; Delaunay, T.; Naeem, R.; Carey, V.J.; Richardson, A.L.; Weinberg, R.A. Stromal Fibroblasts Present in Invasive Human Breast Carcinomas Promote Tumor Growth and Angiogenesis through Elevated SDF-1/CXCL12 Secretion. Cell 2005, 121, 335-348. [CrossRef] [PubMed]

57. Aghi, M.; Cohen, K.S.; Klein, R.J.; Scadden, D.T.; Chiocca, E.A. Tumor stromal-derived factor-1 recruits vascular progenitors to mitotic neovasculature, where microenvironment influences their differentiated phenotypes. Cancer Res. 2006, 66, 9054-9064. [CrossRef] [PubMed]

58. Liu, B.Y.; Soloviev, I.; Chang, P.; Lee, J.; Huang, X.D.; Zhong, C.; Ferrara, N.; Polakis, P.; Sakanaka, C. Stromal cell-derived factor-1/CXCL12 contributes to MMTV-Wnt1 tumor growth involving Gr1+CD11b+ cells. PLoS ONE 2010, 5, e8611. [CrossRef] [PubMed] 